Purdue University

Purdue e-Pubs

IMPACT Publications

Instruction Matters: Purdue Academic Course

Transformation (IMPACT)

2017

\title{
The Effect of Relevance Strategies on Student Perceptions of Introductory Courses
}

Heather N. Fedesco

Colorado College

Ashley Kentner

Purdue University

Jane Natt

Purdue University

Follow this and additional works at: https://docs.lib.purdue.edu/impactpubs

Part of the Educational Assessment, Evaluation, and Research Commons, and the Scholarship of Teaching and Learning Commons

\section{Recommended Citation}

Fedesco, H.N., Kentner, A., \& Natt, J. (2017). The effect of relevance strategies on student perceptions of introductory courses. Communication Education, (66)2, 196-209, doi: 10.1080/03634523.2016.1268697

This document has been made available through Purdue e-Pubs, a service of the Purdue University Libraries. Please contact epubs@purdue.edu for additional information. 
The Effect of Relevance Strategies on Student Perceptions of Introductory Courses

Heather N. Fedesco, Ashley Kentner, \& Jane Natt

Heather N. Fedesco (Ph.D., 2015, Purdue University) is a Mellon Pedagogy Researcher in the Office of the President at Colorado College. Ashley Kentner (M.A., 2014, Purdue University) is a graduate student in the Linguistics Department at Purdue University. Jane Natt (M.A., 1999, University of North Carolina-Chapel Hill) is an Associate Professor in the Brian Lamb School of Communication at Purdue University. Correspondence to: Heather N. Fedesco, Office of the President, Colorado College, Spencer Center, Colorado Springs, CO 80903, U.S.A. Tel: 719389-6705. Email: hfedesco@gmail.com. 


\begin{abstract}
The purpose of this study was to test whether increasing the relevancy of course assignments in a large multi-section introductory public speaking course would lead to improvements in student perceptions of course outcomes. Survey responses from 1,878 students were analyzed to test whether differences exist between students enrolled in classes held during the Spring 2015 semester and those enrolled in classes held in Fall 2015 during which the more relevant course assignments were incorporated. Results reveal that increasing the relevancy of assignments is associated with greater perceived course relevance, motivation for participating in the class, and perceptions of learning. This course redesign demonstrates that simply altering course assignments can positively impact student perceptions and motivation for participating in the class in multi-section introductory courses.
\end{abstract}

Keywords: Enhancing Course Relevance, Introductory Courses, Multi-section courses, Course Assignments, Student Perceptions 
The Effect of Relevance Strategies on Student Perceptions of Introductory Courses College students typically perceive required introductory courses more negatively than elective coursework, especially when the course falls outside their area of concentration. They may perceive these mandatory courses as irrelevant and hence, a waste of time (Neath, 1996). These attitudes contribute to the consistent finding that introductory required courses have lower course ratings compared to their elective counterparts as measured by course evaluation surveys (see reviews by Neath,1996; Wachtel, 1998; Salmon, Smith, Lee, and Miller, 2005). Despite the debate about how valuable course evaluations are and what role/function they should have in academia, student perceptions of an introductory course still have significant implications for the department in which it resides. After all, 100-level courses often provide a student with his or her first exposure to the specific field. When students feel these required introductory courses are more meaningful, it leaves them with lasting positive impressions of the discipline as a whole (Chambliss \& Takacs, 2014). In fact, studies show that redesigning introductory level courses in order to improve the learning experience can lead to greater success at recruiting undergraduate majors or getting non-majors to take additional courses in the discipline (Forte \& Guzdial, 2004; 2005; Kaplan, 2004).

The question then arises: how can instructors foster positive educational experiences in required introductory level courses? Intuitively speaking, if students perceived the course as being relevant to their future classes or careers, then perhaps they would have more positive views of the course, including improved motivations for participating in the class. In turn, this increased student motivation should lead to a host of benefits including improvements in perceptions of learning and course satisfaction (Filak \& Sheldon, 2008; Jang, Reeve, Ryan, \& Kim, 2009; Levesque-Bristol, Knapp, \& Fisher, 2010). 
Keller's (1987) ARCS model supports this notion. The ARCS model is a method that provides instructors with strategies that can be used to enhance student motivation. It identifies relevance as one of four main conditions that should be met in order to increase motivation (attention, confidence, and satisfaction are the other three conditions). In order to enhance the relevance of a course, the model suggests that instructors should strive to answer the question, "why do I have to study this?" Thus, when instructors incorporate relevance strategies, such as explicitly linking instruction to present and future academic/career opportunities, then students are more likely to perceive the value of the lesson and thus, become and stay motivated in the class. Previous research supports this assumption of the ARCS model, showing that relevance correlates positively with beneficial student outcomes (e.g., motivation, course satisfaction; Denson, Loveday, \& Dalton, 2010; Frymier \& Shulman, 1995; Roszkowski \& Soven, 2010).

\section{Enhancing Course Relevance}

Researchers have operationalized relevance in a number of ways. Perhaps the most notable way of enhancing perceived relevance is to explicitly state the rationale of each in-class activity or assignment (Keller, 1987). In this way, the onus is on the individual instructor to employ relevance-enhancing strategies such as connecting the content to current events, providing examples drawn from situations the students are likely to have experienced, or explaining why the subject matter is important. Newby (1991) found that elementary school teachers' use of such relevance strategies corresponded positively with students' on-task time. Frymier and Shulman (1995) were able to further demonstrate that relevance behaviors on the part of the instructor correspond positively with state (as opposed to trait) motivation. It appears, then, that when instructors explicitly make connections between course content and students' lives, they can enhance the relevance of introductory courses, which ultimately impacts student 
motivation. While this solution is viable for individual instructors, it may not be easy to implement across a large, multi-section course.

For introductory communication courses, depending on the size of the university, there could be between a dozen and several hundred sections of this course offered in a given year that are taught by numerous instructors. In order to enhance perceived relevance within a course via instructor behaviors, course directors would have to rely on all instructors to regularly employ these relevancy strategies. It would be impractical to have course directors observe whether instructors are promoting the relevance of course material every day, thus making it impossible for directors to be certain that their instructors are making these connections for their students. Apart from the impracticalities of enforcing instructor relevancy behaviors, course directors overseeing large multi-section introductory courses face additional challenges in ensuring that their instructors are utilizing relevance-enhancing behaviors. Morreale, Scott, Backlund and Simonds (2016) found that at four-year institutions, graduate teaching assistants were the second most frequent people to teach the introductory course (behind adjuncts), suggesting that a large portion of introductory communication courses at four-year institutions are likely to be staffed by graduate students with less teaching experience. This may be problematic when it comes to enhancing relevance in the course. Webster, Villora and Harvey (2012) found that award-winning teachers with 10 or more years of teaching experience were more likely to emphasize course content relevance than novice instructors were with five or less years of teaching experience. Thus, it appears that relevancy-enhancing strategies may be a nuanced pedagogical skill developed over time. Despite adequate training, newer instructors may need more practice in order to fully develop this teaching strategy. 
Of course, one should not assume that all universities can offer comprehensive training programs to improve the pedagogical skills of their instructors. Morreale, Worley, and Hugenberg (2010) found that almost $75 \%$ of participants they surveyed stated they offered one day of training or less to new instructors, with the majority of institutions not offering any training before teaching the class. This might explain why several four-year institutions frequently list instructor qualifications as one of their biggest problems in teaching or supervising introductory communication courses (Morreale et al., 2016). Rapid turnover rates compound this challenge. For instance, graduate teaching assistants at the university where this study takes place typically only teach this course in their first and second year and then move on to other courses; other universities may have similar experiences. This level of turnover suggests that even if departments spent more time training new instructors to include relevance-enhancing strategies, these efforts may be inefficient. Simply put, there are a myriad reasons course directors may have difficulty ensuring that all instructors are emphasizing the relevance of course content across all sections.

Rather than relying solely on instructor behaviors to enhance course relevance, course directors may have more control over course materials and could incorporate assignments with a higher degree of relevancy in an effort to increase perceptions of course value and importance across all sections. More recent research has examined the impact of enhancing relevance through course design. For example, Finney and Pyke (2008) studied the effects of using case studies involving local businesses owned or managed by alumni at a business school. Analyses revealed that students felt they could better relate to these case studies; perceptions of content relevance also correlated positively with motivation. In addition, Roszkowski and Soven (2010) observed that the perceived usefulness of a training program was highly correlated with 
perceived amount learned and also predicted overall satisfaction with the training program.

Other scholars have found that a course's perceived usefulness and relevance to future careers predicted overall course satisfaction (Denson et al., 2010; Richardson, Slater, \& Wilson, 2007).

Taken together, previous research suggests that course directors may be able to surmount some of the challenges associated with enhancing relevance in large multi-section introductory courses through course and material design. That is, by ensuring that course assignments are more relevant, students may perceive the overall course as more relevant, they may have greater motivation for taking the course, as well as greater course satisfaction and perceptions of learning.

\section{Improving Student Perceptions and Motivation}

The ultimate goal of this project is to increase the relevancy of course assignments in a large multi-section introductory communication course in order to improve perceptions of course relevance, motivation for participating in the class, course satisfaction, and perceptions of learning. We acknowledge that a major goal of course redesign efforts is to improve actual student learning; however, there are other measurable and incremental benefits to course redesigns, including increasing student enrollment and engagement (Lo \& Prohaska, 2011; Squires, Faulkner \& Hite, 2009); creating stronger links between theory and practice (Hammerness \& Darling-Hammond, 2002) and teaching students to value course content and its connection to real life (Rose \& Torosyan, 2009). In this project, we focus on student perceptions and motivation and argue that seeking to improve these affective and motivational domains is an equally valuable endeavor.

There are several advantages that emerge from increasing student affect and motivation. For example, Isen and Reeve (2005) found that positive affect promotes intrinsic motivation. In 
fact, they demonstrated that positive affect can lead to "forward-thinking, self-control, and the ability to stay on task, even on a task that may be uninteresting or unpleasant" (p. 318). Additional evidence suggests that positive perceptions of a course may create conditions that could enable instructors to optimize cognitive outcomes (e.g., Kerssen-Griep, Trees, \& Hess, 2008).

Improving student affective domains also provides beneficial outcomes to the field as a whole, particularly in the case of a large multi-section required introductory public speaking class. That is, the experiences students have in their introductory courses have profound effects on their perceptions of the discipline. After following students over the span of eight years, Chambliss and Takacs (2014) observed that because new college students know little about fields not typically covered in high school, the first college course they take in a new field comes to represent the discipline as a whole. In their research, they found that a good experience in these introductory courses often times enticed students to switch majors and embark on a new academic trajectory. Similarly, a bad experience deterred students from taking courses in that field. The authors state, "Especially if the subject matter is new, an unpleasant first experience certainly may make students skeptical of the department, and fairly often diminishes their impression of the entire discipline" (p. 53). If communication instructors can demonstrate that their introductory courses are relevant and thus, worthy of their time, it can lend more legitimacy to the discipline and hopefully attract a new generation of communication scholars.

As previously stated, it would certainly be ideal to establish that a course redesign effort improves actual student learning, for example, by demonstrating that students made improvements on course assignments. However, for the course redesign in this study, the course director altered the course assignments themselves, making it impossible to test whether students 
improved on a standardized assessment. Thus, we limited the focus of this study to testing whether increasing relevance of course assignments would lead to improvements in affective and motivational outcomes, including perceptions of learning. Although the correlation between perceptions and actual learning is generally quite small, this correlation is higher for judgments of improvements in interpersonal skills such as public speaking (Sitzmann, Ely, Brown, \& Bauer, 2010). That is, students are better able to perceive how much public speaking skills they have developed as compared to other types of knowledge. Other scholars suggest that perceptions of learning is indicative of students' course satisfaction and their motivation to apply the knowledge they have learned (Sitzmann et al., 2010). Having students feel as if they are motivated to apply the skills they have learned and that they had a satisfying course experience are notable outcomes. As Bacon (2016) states, "we want our students to have a positive experience, to spread positive word of mouth about our programs, and to remember their experiences fondly after they graduate" (p. 4).

Taken together, seeking to improve the affective experience and motivation of students in a large multi-section introductory public speaking course can lead to numerous benefits for the student and the discipline and thus is a worthy goal. To this end, we designed assignments that will allow students to practice more relevant skills, which should lead students enrolled in sections with redesigned assignments to perceive these courses as being more relevant at the end of the semester. Thus, we pose the following hypothesis:

H1: Students enrolled in sections of an introductory communication course that include relevant course assignments throughout the term, compared to those enrolled in sections with less relevant assignments, perceive the course to be more relevant at the end of the semester. 
According to the ARCS model, courses that students perceive to be more relevant should see higher levels of student motivation for participating in that course; thus, we pose the second hypothesis:

$\mathrm{H} 2$ : Students enrolled in sections of an introductory communication course that include relevant course assignments throughout the term, compared to those enrolled in sections with less relevant assignments, report higher levels of motivation for participating in the course.

Based on the review of the literature, the increase in perceived relevance of course material is associated with an increase in course satisfaction and perceptions of learning, which leads to the third hypothesis:

H3: Students enrolled in sections of an introductory communication course that include relevant course assignments throughout the term, compared to those enrolled in sections with less relevant assignments, have higher levels of (a) course satisfaction and (b) perceptions of learning.

\section{Methods}

\section{Participants}

Students who participated in this study were enrolled in the introductory public speaking course at a large Midwestern university. This course is part of the core curriculum and is required by all but three majors. All instructors in the Spring semester had previously taught the course for at least one semester. Conversely, in the Fall semester about half of the instructors were either new to teaching, or new to teaching this specific course. In order to remove any effects that lack of teaching experience might have on the results, only data from courses where the instructor had previously taught the public speaking course for at least one semester were 
included in the analyses. Thus, the sample consisted of 2,504 students ( $35.8 \%$ female) enrolled during the Spring $2015(N=1,851)$ and Fall $2015(N=653)$ semesters. In the Spring semester, 77 sections taught by 42 instructors met our criteria. In the Fall semester, 27 sections taught by 18 instructors met our criteria. ${ }^{1}$ The students ranged in age from 18 to $33(M=19.6, S D=1.1){ }^{2}$ Eighteen percent of students were freshman, $61.6 \%$ were sophomores, $15.8 \%$ were juniors, and $4.6 \%$ were seniors. The majority of students were White (60.3\%), followed by International (20.3\%), Asian (7.9\%), Hispanic/Latino (4.7\%), Black/African American (2.5\%), Mixed Race (2.2\%), unknown (1.9\%), and American Indian/Alaska Native and Native Hawaiian/Other Pacific Islander $(0.1 \%)$. Of these students, 1,878 (75\%) completed course evaluations (Spring 2015, $N=1,392 ;$ Fall 2015, $N=486)$ and $844(33.7 \%)$ completed a student perceptions survey (described below; Spring 2015, $N=520$; Fall 2015, $N=324$ ).

\section{Intervention}

Over the years, students consistently noted that the current speaking assignments were irrelevant and had nothing to do with their majors. In response to this criticism and in an effort to create an intervention that would effectively enhance the relevance of the public speaking course, the course director met with the assistant head for first-year engineering and with faculty from a variety of disciplines (e.g., pharmacy, technology, English) to identify communication skills that incoming first-year students would use in major classes. Instructors both within the communication department and across campus observed students were often unable to equate presentation assignments and skills learned in the public speaking course with presentations they were making in courses in their majors; this necessitated a change in the public speaking course.

Feedback from the course director's meetings informed what types of changes would be valuable. In particular, the need for greater emphasis on narrative, process explanations, and 
asynchronous instructional skills became obvious. Through discussions with faculty from the pharmacy department, for example, it became evident that there was a need for students to develop the skill of communicating narratives, which resembled the format students would use to deliver oral patient drug reports. The need for students to be able to provide simple process explanations also became apparent. For instance, engineers need to be able to present projects to non-scientific stakeholders - such as donors and promotions departments - who often need an explanation of the engineering processes and terms. The need for how-to narrated PowerPoint presentations (i.e., asynchronous instructional presentations) was deemed relevant because more majors on campus (including engineering) are replacing some traditional face-to-face class with video and multimedia presentations to both simulate real world scenarios and save actual class time. Finally, the inclusion of two status reports for the group presentation allowed students to develop a communication skill used commonly in the business world (i.e., giving updates on long-term projects). Table 1 provides a comparison of pre- and post-intervention assignments.

\section{[Insert Table 1]}

In addition to making connections between course material and contexts outside the classroom, the course director made efforts to increase relevance within the context of the class with the inclusion of formative assignments. After students received feedback on the narrative assignment, they were able to incorporate that feedback before using the same narrative (in a shortened form) as either an attention-gaining device or support in their persuasive presentations. Similarly, students received feedback on the simple explanation before they could incorporate it as one element of the instructional presentation. Knowing that the narrative and simple explanation assignments would need to be included in other presentations later in the semester likely increased the initial relevance of those assignments. 
It is important to note that although instructors were encouraged to emphasize the relevance of all assignments, these connections were explicitly made in the assignment instructions, which were included at the end of the textbook. Thus, if an instructor did not clearly make connections between the assignment and students' future courses, careers, or personal life, students still saw these connections on the assignment page.

\section{Procedure and Materials}

Students in the Spring 2015 and Fall 2015 semesters received an online student perceptions survey at the end of the semester, which was administered as part of a larger program assessment initiative conducted by the university (IMPACT, 2015). Students also completed course evaluations at the end of the semester collected through the CourseEval software system. Participation was voluntary, though instructors were encouraged to offer a small amount of participation points to incentivize students to fill out the survey and course evaluation. Both the survey and the course evaluations were intended to measure the following constructs: perceived course relevance, motivation for participating in the course, course satisfaction, and perceptions of learning.

Relevance. The six-item Perceived Knowledge Transfer Scale (PKTS; Levesque-Bristol, Zissimopoulos, Richards, Wang, \& Yu, 2016) assessed relevance of course material (e.g., Ifeel as if the material covered in this course is relevant to my future career; Information learned in this course will inform my future learning experiences). The measure uses a 7-point scale $(1=$ strongly disagree; $7=$ strongly agree) with higher scores indicating greater perceived relevance. Internal consistency was very strong (Cronbach's $\alpha=.96)$. In addition, the general item, the course content was relevant to me, was added to the course evaluations survey and was rated on a 5 -point scale $(1=$ strongly disagree; $5=$ strongly agree $)$. 
Motivation. The Situational Motivation Scale (SIMS; Guay, Vallerand, \& Blanchard, 2000; Levesque-Bristol et al., 2010) was adapted to measure motivation to participate in the course. The 18-item scale includes three items to measure each of the six forms of motivation (see Deci \& Ryan, 2000). Positive forms of motivation include intrinsic motivation, integration, and identification, while introjection, extrinsic motivation, and amotivation comprise negative forms of motivation. Intrinsic motivation underlies activities that are interesting, enjoyable and provide inherent satisfaction. Integration occurs when people pursue activities because they are an integral part of who they are. Identification accompanies the performance of actions that one deems personally important. Introjection underlies behaviors performed to enhance ego or avoid negative states, such as guilt or anxiety. Extrinsic motivation occurs when individuals engage in behaviors to receive a reward or avoid punishment. Finally, amotivation represents a lack of motivation and underlies behaviors that one performs without purpose.

Participants were given the prompt "Why are you participating in this class?" and then responded to the SIMS items on a 7 -point scale ( $1=$ strongly disagree; $7=$ strongly agree $)$. Example items include, because I really enjoy it (intrinsic motivation), because it allows me to develop skills that are important to me (identification), and because I feel I have to (extrinsic motivation). The motivation sub-scales had strong internal consistency (Cronbach's $\alpha$ ranged from .80 to .96$)$.

Course satisfaction. A general question, Overall, I would rate this course as, was used to assess course satisfaction. In addition, the question, Overall, I would rate this instructor as, was used as a control variable. Both items appeared on course evaluations and were assessed on a 5 -point scale $(1=$ very poor; $5=$ excellent $)$. 
Perceptions of learning. Three items were included on course evaluations that assessed student perceptions of learning (e.g., As a result of your work in this class, what gains did you make in the skill of demonstrating effective, professional delivery) using a 5-point scale ( $1=\mathrm{I}$ gained nothing at all; $5=$ I gained a great deal). Internal consistency for perceptions of learning was excellent (Cronbach's $\alpha=.95)$.

\section{Results}

Analyses tested whether differences existed between pre- (Spring 2015) versus post- (Fall 2015) intervention courses on student perceptions and motivation for participating in the course. To test the hypotheses, we ran one-way ANCOVAs with condition (pre- versus postintervention) as the independent variable and perceived relevance (PKTS and course evaluation item), the six forms of motivation for participating in the course, course satisfaction, and perceptions of learning serving as dependent variables. Student age, sex, international student status, and underrepresented minority status served as covariates. Final grade in the course and instructor rating were also included as covariates to control for variability in teaching quality. Table 2 reports the results of these ANCOVAs. All partial eta squared values were .01 or less and thus are not reported in the table.

[Insert Table 2]

H1 predicted that students in the intervention sections would perceive the course to be more relevant at the end of the semester compared to those in the pre-intervention sections. Results based on the two operationalizations of relevance - PKTS $(p=.01)$ and the course evaluation item $(p=.008)$ - were in support of H1 suggesting that students in the intervention condition perceived the course to be more relevant. 
$\mathrm{H} 2$ stated that those in the intervention condition would have improved motivation for participating in the course. The data partially supported this hypothesis. Students in the intervention condition saw increases in two positive forms of motivation for taking the course, intrinsic motivation (behaviors performed for enjoyment; $p=.027$ ) and identification (behaviors performed because they are personally important; $p=.005)$. Students in the intervention condition also saw a decrease in one negative form of motivation, extrinsic motivation (behaviors performed to receive a reward or avoid punishment; $p=.016$ ).

$\mathrm{H} 3 \mathrm{a}$ predicted that students in the intervention condition would rate the course more favorably compared to those in the pre-intervention condition. The data did not support this hypothesis; there was no statistical difference in course satisfaction between the two conditions. In contrast, the results supported $\mathrm{H} 3 \mathrm{~b}$ (students' perceptions of learning would increase in the intervention condition; $p=.03$ ). Those in the intervention condition felt they acquired more skill gains compared to those in the pre-intervention condition.

\section{Discussion}

The major purpose of this project was to redesign a large multi-section introductory communication course in order to improve perceived course relevance. In doing so, we conducted an intervention to alter course assignments in an effort to make them more relevant to students. We sought to test whether this change influenced the degree to which students perceived the course as a whole to be relevant at the end of the semester. We also predicted that if students perceived the course to be more relevant, then they should report higher levels of motivation for participating in the course, course satisfaction, and perceptions of learning.

Across two indicators of perceived course relevance, results revealed that the alterations made to course assignments did in fact lead to greater perceptions of course relevance at the end 
of the semester. These findings support the research that shows how the packaging of course material can be an effective strategy to increase perceived relevance (Finney \& Pyke, 2008; Roszkowski \& Soven, 2010). In addition, this study adds to the literature by explicitly comparing less relevant versus more relevant content and assignments.

Public speaking sections that included relevant assignments also saw improvements to students' motivation for participating in the class, which supports the tenets of the ARCS model (Keller, 1987). Students reported higher levels of intrinsic motivation and identification suggesting that they were more likely to report that the reason they are participating in the class was because they enjoyed the material, and because they deemed it personally important as compared to students in the pre-intervention condition. It is interesting to note that although this course was required - which by definition affects perceptions of extrinsic motivation - students still reported lower levels of extrinsic motivation in the post-intervention condition. That is, they were less likely than those in the pre-intervention condition to state that they were participating in the class to receive a reward or avoid punishment. These results extend the tenets of the ARCS model by providing another strategy that can be used to enhance course relevance. In addition to having instructors explicitly articulate course content relevance, perceptions of relevance can also be increased by enhancing the relevancy of course assignments. Moreover, this study specifies the types of motivation that are influenced when relevant assignments are incorporated in required introductory courses.

Although students in the post-intervention group found the course more relevant, they did not have higher levels of course satisfaction ratings. Of course, there are multiple factors that may influence a students' rating of a class. Despite our efforts to control for several of these factors (e.g., final grades, instructor rating), others remain unmeasured, which may have 
influenced the results. One possible explanation is that the first iteration of a course redesign can be somewhat turbulent (Felder \& Brent, 1996). The larger the course overhaul, the more turbulent the implementation might be, especially when the execution of the implementation is in the hands of dozens of other instructors. The fact that students in the intervention condition did not report lower levels of course satisfaction is encouraging.

Contrary to the course satisfaction results, students in the intervention condition reported greater perceptions of learning. These results support and extend those found by Roszkowski and Soven (2010). While the authors found correlations between perceived usefulness of and perceptions of learning in a training program, this study specifically compared course sections and found that students reported greater learning gains in courses with relevant assignments. As discussed previously, perceptions of learning is not the same as actual learning, and instead may be more indicative of course satisfaction and motivation to apply knowledge (Sitzmann et al., 2010). The current data support this supposition; statistically significant $(p<.01)$ large correlations were found between perceptions of learning and course satisfaction $(r=.65)$, intrinsic motivation $(r=.53)$, integration $(r=.47)$, and identification $(r=.58)$. Thus, while perceptions of learning may not necessarily represent actual knowledge gained in the course, it is still associated with desirable outcomes (i.e., course satisfaction, motivation) for an introductory public speaking course. In order to test the effects that incorporating relevant course assignments has on actual learning, future research should test whether students in sections with more versus less relevant course assignments perform better on a summative presentation that has been evaluated by two experienced public speaking judges (to ensure consistency in grading). 
As with any research design, these results should be considered in light of the context in which they were studied. As previously mentioned, the changes to the course were executed during the Fall semester. Given that the introductory communication course under investigation in the current project is staffed largely by graduate teaching assistants, the Fall semester sections are taught mostly by instructors who are new to the university and are thus new to teaching or new to teaching this specific course. In order to account for this fact, we only analyzed data associated with instructors who had previously taught the course. Yet those who have already taught the course still had to adjust to the redesigned assignments, which affected things like the course schedule and previously utilized lesson plans, and created more opportunities for classroom turbulence. Given that the course saw improvements across a variety of important variables despite the increased likelihood for a bumpy semester speaks to the strength of the intervention. Future research could compare similar semesters (i.e., Spring 2015 versus Spring 2016) to factor out any influence that differences in the time of year has while also allowing more time for the implementation of the intervention to be smoothed out.

Future research studies might also expand the conceptualization of course relevance. In the current study, the course director met with faculty from other disciplines to identify skills they deem important for students to possess in order to make them successful in their major and career. The degree to which skills are perceived to be useful in future coursework and professions is certainly an important component of perceived relevance; however, students might also be interested in applying these skills in other aspect of their lives. Future research should explore other relevant contexts for which students might wish to apply their skills and tailor speaking assignments to those contexts. In doing so, perhaps assignments can be created that 
focus on non-public speaking contexts while still allowing students to practice oral communication skills necessary for the professional workplace and other aspects of their lives.

\section{Implications}

Course directors struggle with creating a consistently positive learning experience for students across all sections of a given course. This study provides one viable and relatively easyto-implement solution to help address this challenge commonly found in large multi-section introductory communication courses. Course directors can enhance the degree to which students perceive a course to be relevant by simply implementing assignments that will allow students to develop and practice skills that they will more likely use in their future classes and careers. Rather than relying solely on instructor behaviors, course directors can create more relevant assignments that improve (a) perceived course relevance, (b) motivation for participating in the course, and (c) perceptions of learning. In turn, these improvements may lead to more positive perceptions of the discipline and provides a more inviting door for future communication scholars to enter.

\section{Acknowledgements}

The authors would like to thank Debra Runshe for her assistance on this paper. 


\section{References}

Bacon, D. R. (2016). Reporting actual and perceived student learning in education research. Journal of Marketing Education, 38, 3-6. doi:10.1177/0273475316636732

Chambliss, D. F., \& Takacs, C. G. (2014). How college works. Cambridge, MA: Harvard University Press.

Deci, E. L., \& Ryan, R. M. (2000). The "what" and "why" of goal pursuits: Human needs and the self-determination of behavior. Psychological Inquiry, 11, 227-268. doi:10.1207/s15327965pli1104_01

Denson, N., Loveday, T., \& Dalton, H. (2010). Student evaluation of courses: What predicts satisfaction? Higher Education Research \& Development, 29, 339-356. doi:10.1080/07294360903394466

Felder, R. M., \& Brent, R. (1996). Navigating the bumpy road to student-centered instruction. College Teaching, 44, 43-47. doi:10.1080/87567555.1996.9933425

Filak, V. F., \& Sheldon, K. M. (2008). Teacher support, student motivation, student need satisfaction, and college teacher course evaluations: Testing a sequential path model. Educational Psychology, 28, 711-724. doi:10.1080/01443410802337794

Finney, S. \& Pyke, J. (2008). Content relevance in case-study teaching: The alumni connection and its effect on student motivation. Journal of Education for Business, 83, 251-258. doi:10.3200/JOEB.83.5.251-258

Forte, A., \& Guzdial, M. (2004, January). Computers for communication, not calculation: Media as a motivation and context for learning. Paper presented at the Hawaii International Conference on System Sciences, Big Island, HI. 
Forte, A., \& Guzdial, M. (2005). Motivation and nonmajors in computer science: Identifying discrete audiences for introductory courses. IEEE Transactions on Education, 48, 248253. doi:10.1109/TE.2004.842924

Frymier, A. B. \& Shulman, G. M. (1995). "What's in it for me?": Increasing content relevance to enhance students' motivation. Communication Education, 44, 40-50. doi:10.1080/03634529509378996

Guay, F., Vallerand, R. J., \& Blanchard, C. (2000). On the assignment of situational intrinsic and extrinsic motivation: The situational motivation scale (SIMS). Motivation and Emotion, 24, 175-213. doi:10.1023/a:1005614228250

Hammerness, K., \& Darling-Hammond, L. (2002). Meeting old challenges and new demands: The redesign of the Stanford Teacher Education Program. Issues in Teacher Education, $11,17-30$.

IMPACT Management Team and IMPACT Assignment Team (2015). Annual IMPACT Report 2015: A report by the IMPACT Data Collection and Analysis Team, Parts 1 and 2. IMPACT Reports, 6. Retrieved from http://docs.lib.purdue.edu/impactreps/6

Isen, A. M., \& Reeve, J. (2005). The influence of positive affect on intrinsic and extrinsic motivation: Facilitating enjoyment of play, responsible work behavior, and selfcontrol. Motivation and Emotion, 29, 295-323. doi:10.1007/s11031-006-9019-8

Jang, H., Reeve, J., Ryan, R. M., \& Kim, A. (2009). Can self-determination theory explain what underlies the productive, satisfying learning experiences of collectivistically oriented Korean students? Journal of Educational Psychology, 101, 644-661. doi:10.1037/a0014241 
Kaplan, D. (2004). Courses for nonmajors: Teaching computation to undergraduate scientists. Paper presented at the SIGCSE Technical Symposium on Computer Science Education, New York.

Keller, J. M. (1987). Development and use of the ARCS model of instructional design. Journal of Instructional Development, 10, 2-10. doi:10.1007/bf02905780

Kerssen-Griep, J., Trees, A. R., \& Hess, J. A. (2008). Attentive facework during instructional feedback: Key to perceiving mentorship and an optimal learning environment. Communication Education, 57, 312-332. doi:10.1080/03634520802027347

Levesque-Bristol, C., Knapp, T. D., \& Fisher, B. J. (2010). The effectiveness of service-learning: It's not always what you think. The Journal of Experiential Education, 33, 208-224. doi:10.5193/jee33.3.208

Levesque-Bristol, C., Zissimopoulos, A., Richards, K., Wang, C., \& Yu, S. (2016). Creation and validation of the perceived knowledge transfer scale (PKTS). Manuscript submitted for publication, Purdue University.

Lo, C. C., \& Prohaska, A. (2011). Creating an environment conducive to active and collaborative learning: Redesigning Introduction to Sociology at a large research university. Journal on Excellence in College Teaching, 24, 75-98.

Morreale, S. P., Myers, S. A., Backlund, P. M., \& Simonds, C. J. (2016). Study IX of the basic communication course at two- and four-year U.S. colleges and universities: A reexamination of our discipline's “front porch". Communication Education, 65, 338-355. doi: 10.1080/03634523.2015.1073339 
Morreale, S., Worley, D. W., \& Hugenberg, L. (2010). The basic communication course at twoand four-year US colleges and universities: Study VIII-The 40th anniversary. Communication Education, 59, 405-430. doi:10.1080/03634521003637124

Neath, I. (1996). How to improve your teaching evaluations without improving your teaching. Psychological Reports, 78, 1363-1372. doi:10.2466/pr0.1996.78.3c.1363

Newby, T. J. (1991). Classroom motivation: Strategies of first-year teachers. Journal of Educational Psychology, 83, 195. doi:10.1037/0022-0663.83.2.195

Richardson, J. T., Slater, J. B., \& Wilson, J. (2007). The national student survey: Development, findings and implications. Studies in Higher Education, 32, 557-580. doi:10.1080/03075070701573757

Rose, M. \& Torosyan, R. (2009). Integrating big questions with real-world applications: Graduate redesign in philosophy and art history. New Directions for Teaching and Learning, 2009, 61-70. doi:10.1002/t1.365

Roszkowski, M. J. \& Soven, M. (2010). Did you learn something useful today? An analysis of how perceived utility relates to perceived learning and their predictiveness of satisfaction with training. Performance Improvement Quarterly, 23, 71-91. doi:10.1002/piq.20082

Salmon, C. T., Smith, S. W., Lee, B., \& Miller, V. D. (2005). Exploring assorted beliefs, doubts, and legends regarding quantitative teaching evaluations. Journalism and Mass Communication Educator, 60, 257-271. doi:10.1177/107769580506000305

Sitzmann, T., Ely, K., Brown, K. G., \& Bauer, K. N. (2010). Self-assessment of knowledge: a cognitive learning or affective measure? Academy of Management Learning \& Education, 9, 169-191. doi:10.5465/amle.2010.51428542

Squires, J., Faulkner, J., \& Hite, C. (2009). Do the math: Course redesign's impact on learning 
and scheduling. Community College Journal of Research and Practice, 33, 883-886. doi: $10.1080 / 10668920903149723$

Wachtel, H. K. (1998). Student evaluation of college teaching effectiveness: A brief review. Assignment and Evaluation in Higher Education, 23, 191-212. doi:10.1080/0260293980230207

Webster, C. A., Villora, S. G., \& Harvey, R. (2012). Physical education teachers' self-reported communication of content relevance. Physical Educator, 69, 89-103. 


\section{Endnotes}

${ }^{1}$ In order to remove possible confounds, we omitted specialty sections of the public speaking course (e.g., honors, online, learning communities, etc.) from analyses.

${ }^{2}$ We omitted students under the age of 18 from analyses. 
Appendix A: Tables

Table 1

Comparison of Pre- and Post-Intervention Assignments

\begin{tabular}{|c|c|}
\hline Pre-Intervention Assignments & Post-Intervention Assignments \\
\hline $\begin{array}{l}\text { Individual Informative Presentation } 1 \\
\text { - } 3-5 \text { minutes } \\
\text { - Innovative and unknown person } \\
\text { - } \quad 4-6 \text { minutes } \\
\text { - New Discovery } \\
>\text { Individual Persuasive Presentation } \\
\text { - } 5-7 \text { minutes } \\
\text { - Question of fact, value or policy } \\
\text { Group Persuasive Presentation } \\
\text { - Approximately } 30 \text { minutes } \\
\text { - Committee grant to fix problem on } \\
\text { campus }\end{array}$ & $\begin{array}{l}\text { Individual Narrative Presentation } \\
\text { - } 2-3 \text { minutes } \\
\text { Formative assessment to be used in } \\
\text { Persuasive Presentation (in a } \\
\text { shortened form) } \\
>\quad \text { Individual Simple Quasi-Scientific } \\
\text { Process Explanation Presentation } \\
\text { - } 1-2 \text { minutes } \\
\text { - Formative assessment to be used in } \\
\text { Asynchronous Presentation } \\
\text { Individual Asynchronous Presentation } \\
\text { - } 3-5 \text { minutes } \\
\text { - Instructional narrated PowerPoint } \\
\text { - } 3-5 \text { minutes } \\
\text { - Join/participate in local nonprofit } \\
\text { Group Persuasive Presentation } \\
\text { - Approximately } 15 \text { minutes } \\
\text { - Committee grant to fix problem on } \\
\text { - Incampus } \\
\text { delivered throughout semester }\end{array}$ \\
\hline
\end{tabular}

Table 2

Results of ANCOVAs for Pre-Intervention (Spring 2015) vs. Post-Intervention (Fall 2015)

\begin{tabular}{llll}
\hline & $\begin{array}{l}\text { Pre-Intervention } \\
M(S E) \dagger\end{array}$ & $\begin{array}{l}\text { Post-Intervention } \\
M(S E) \dagger\end{array}$ & $F(\mathrm{dfs})$ \\
\hline Relevance & & & \\
$\quad$ PKTS & $5.08(.06)$ & $5.34(.08)$ & $7.38(1,704)^{* *}$ \\
$\quad$ Course evaluation item & $3.60(.03)$ & $3.73(.04)$ & $7.07(1,1855)^{* *}$ \\
Motivation & & & \\
$\quad$ Intrinsic & $3.67(.07)$ & $3.93(.09)$ & $4.93(1,724)^{*}$ \\
$\quad$ Integration & $4.69(.06)$ & $4.83(.08)$ & $2.43(1,724)$ \\
Identification & $4.62(.06)$ & $4.89(.08)$ & $7.86(1,724)^{* *}$ \\
$\quad$ Introjection & $3.33(.07)$ & $3.20(.09)$ & $1.36(1,724)$ \\
$\quad$ Extrinsic & $5.34(.06)$ & $5.10(.08)$ & $5.84(1,724)^{*}$ \\
$\quad$ Amotivation & $3.02(.06)$ & $2.89(.08)$ & $1.50(1,724)$ \\
Course satisfaction & $3.59(.02)$ & $3.65(.03)$ & $2.48(1,1870)$ \\
Perceptions of learning & $3.47(.02)$ & $3.56(.04)$ & $4.74(1,1863)^{*}$ \\
\hline
\end{tabular}

Note. The range of possible values for all variables is from 1-7, with the exception of the course evaluation relevance item, course satisfaction, and perceptions of learning (values range from 1- 
5). PKTS $=$ Perceived knowledge transfer scale. $\dagger$ Estimated marginal means and standard errors are reported with age, sex, international student status, underrepresented minority status, final grade, and instructor rating as covariates. ${ }^{*} p<.05, * * p<.01$ 